Research

\title{
Association of umbilical cord blood lead with neonatal behavior at varying levels of exposure \\ Archana B Patel ${ }^{1,2}$, Manju R Mamtani2 ${ }^{2}$ Tushar P Thakre*2,3 and \\ Hemant Kulkarni ${ }^{2}$
}

Address: ${ }^{1}$ Clinical Epidemiology Unit, Indira Gandhi Government Medical College, Nagpur, India, ${ }^{2}$ Lata Medical Research Foundation, Nagpur, India and ${ }^{3}$ University of North Texas Health Science Center, Fort Worth, TX, USA

Email: Archana B Patel - archana_patel@vsnl.com; Manju R Mamtani - manjumamtani@rediffmail.com;

Tushar P Thakre* - tthakre@hsc.unt.edu; Hemant Kulkarni - hemant_kulkarnius@yahoo.com

* Corresponding author

Published: 27 June 2006

Behavioral and Brain Functions 2006, 2:22 doi:10.1 I86/1744-908I-2-22
Received: 18 April 2006

Accepted: 27 June 2006

This article is available from: http://www.behavioralandbrainfunctions.com/content/2/1/22

(c) 2006 Patel et al; licensee BioMed Central Ltd.

This is an Open Access article distributed under the terms of the Creative Commons Attribution License (http://creativecommons.org/licenses/by/2.0), which permits unrestricted use, distribution, and reproduction in any medium, provided the original work is properly cited.

\begin{abstract}
Background: In the light of the ongoing debate about lowering the cut-off for acceptable blood lead level to $<5 \mu \mathrm{g} / \mathrm{dL}$ from the currently recommended level of $<10 \mu \mathrm{g} / \mathrm{dL}$, we considered whether prenatal exposure to varying levels of lead is associated with similar or disparate effects on neonatal behavior.
\end{abstract}

Methods: Using Brazelton's Neonatal Behavioral Assessment Scale (NBAS), an epidemiological approach and robust statistical techniques like multivariate linear regression, logistic regression, Poisson regression and structural equations modeling analyses we estimated the simultaneous indirect effects of umbilical cord blood lead (CBL) levels and other neonatal covariates on the NBAS clusters.

Results: We observed that when analyzed in all study subjects, the CBL levels independently and strongly influenced autonomic stability and abnormal reflexes clusters. However, when the analysis was restricted to neonates with $\mathrm{CBL}<10 \mu \mathrm{g} / \mathrm{dL}, \mathrm{CBL}$ levels strongly influenced the range of state, motor and autonomic stability clusters. Abnormal walking reflex was consistently associated with an increased CBL level irrespective of the cut-off for CBL, however, only at the lower cut-offs were the predominantly behavioral effects of CBL discernible.

Conclusion: Our results further endorse the need to be cognizant of the detrimental effects of blood lead on neonates even at a low-dose prenatal exposure.

\section{Background}

There is an ongoing debate over the appropriate cut-off of blood lead concentration to detect lead poisoning [1-6]. Starting from $60 \mu \mathrm{g} / \mathrm{dL}$ the cut-off recommended by the Centers for Disease Control (CDC) receded to $25 \mu \mathrm{g} / \mathrm{dL}$ and then to the currently used value of $10 \mu \mathrm{g} / \mathrm{dL}[5]$. This was essentially due to a series of studies showing that even at low doses of exposure, environmental lead continues to be a biological and social toxicant $[4,5,7,8]$. Recently, there is a burgeoning recognition that even at low doses exposure to lead has serious implications on a child's behavior pattern. For example, lead exposure in low doses has been convincingly implicated in juvenile delinquency $[9,10]$, intelligence quotient (IQ) patterns $[4,11-18]$ and 
crime rates $[19,20]$. In the light of these findings, Needleman and others recommend that the time has arrived to lower the CDC recommended cut-off for blood lead to 5 $\mu \mathrm{g} / \mathrm{dL}[5]$.

Blood lead has also been considered for a long time to be a behavioral teratogen. Interestingly, however, literature on the putative association of the prenatal blood lead exposure with the behavioral prototypes in the newborns is scant and inconsistent [2]. For example, Ernhart et al [21], Rothenberg et al [22] and more recently Emory et al [23] could not demonstrate any striking association between umbilical cord blood lead level and neonatal behavior. In contrast, two recent prospective studies have - using the Mental Development Index (MDI) - shown association of low-exposure to lead with the neurobehavioral development in early life $[24,25]$. Additionally, since neonatal behavior is a multi-dimensional construct with several hard-to-measure and correlated domains, the analytical strategy to test the association between blood lead levels and behavioral indicators is not always straightforward $[2,26]$.

We therefore undertook this study to address two research questions: a) Do umbilical cord blood lead (CBL) levels independently correlate with the early neonatal neurobehavioral pattern? b) Do these neurobehavioral associations, if any, continue to be present in neonates with CBL levels below $10 \mu \mathrm{g} / \mathrm{dL}$ ? We hypothesized that the behavioral archetypes of neonates are influenced by the level of prenatal exposure to lead even at relatively low doses of exposure. To test this hypothesis, we conducted a crosssectional study assessing the association between umbilical cord blood lead levels and the neonatal neurobehavioral responses using appropriate measurement scales and statistical models.

\section{Methods \\ Study subjects}

The present cross-sectional study was conducted at the Government Medical College and Hospital, a tertiary care hospital in Nagpur, India. The data were collected over a four-month period starting from January 1998. All consecutively born neonates at the study center whose mother gave an informed consent were included in the study. Overall, 230 children were included. However, blood lead measurements were available on 176 ( 77\%) of the neonates who comprised our study sample. The study was approved by the Ethical Committee of the Government Medical College, Nagpur, India.

\section{Study variables}

\section{Outcomes}

We measured the neonatal behavior using Brazelton's Neonatal Behavioral Assessment Scale (NBAS) [27]. The scale consists of the 28 behavior-related items scored on a 9-point scale, 18 reflexes and 7 supplementary items. Two trained pediatricians administered the scale. Before the study began, these two investigators independently and together evaluated a separate set of 20 neonates to ensure concordance of observations. The NBAS was administered within three days of birth. Since the arousal state can influence a newborn's performance on the individual items of the NBAS scale [27], we noted the initial state (the state of the newborn at the beginning of the NBAS evaluation) and predominant state (the state which the newborn was most commonly in over the duration of NBAS assessment and which was recorded at the end of the NBAS evaluation) of the newborn. We converted the raw scores on the NBAS items into the following seven clusters as recommended by Lester et al [28]: habituation, orientation, motor, range of state, regulation of state, autonomic stability and abnormal reflexes. The association of the predictor variables was then assessed with the cluster scores.

\section{Blood lead measurement}

Cord blood samples $(5 \mathrm{ml})$ were obtained for each neonate in a metal-free K3 EDTA bulb and analyzed within 48 hours of sample collection for blood lead by flameless atomic absorption spectrophotometry (Hitachi Z-8000) in parts per billion at a wavelength of $283.3 \mathrm{~nm}$ with a slit width of $1.3 \mathrm{~nm}$ using the method described by Lagesson et al [29]. The detection rate of lead for the instrument was $1 \mu \mathrm{g} / \mathrm{l}$, with an average error rate of $5 \%$ for reproducibility of results. The samples were analyzed for estimation of the lead concentration within 48 hours of collection.

\section{Covariates}

Table 1 describes the characteristics of the study subjects. In multiple linear regression analyses (described below), we used the following covariates: maturity, hours of birth, sex, birth weight, head circumference, fetal and maternal obstetric problems, specific disorder in fetus/newborn, problem noted during labor, use of oxytocic agents, rupture of membranes before onset of labor, tobacco intake by the mother and alcohol intake by the mother. The meaning and description of some of these covariates is provided in details in Supplementary Table 1 (see additional file 1 , supplementary table 1 ). The covariates were measured based on the antenatal medical records, labor notes and by interviewing the mothers.

\section{Statistical analysis}

Our general strategy for statistical analysis was to test the association between cord blood lead levels and each NBAS cluster score in univariate and multivariate contexts. Since, in theory, the NBAS clusters represent essentially orthogonal i.e. uncorrelated factors, we used the 
Table I: Characteristics of the neonatal study subjects $(n=176)$

\begin{tabular}{|c|c|}
\hline Maturity in weeks (mean \pm S.D) & $38.93 \pm 3.45$ \\
\hline Hours of birth (mean \pm S.D) & $45.78 \pm 15.15$ \\
\hline \multicolumn{2}{|l|}{ Sex } \\
\hline Male (n, \%) & $99(56.3)$ \\
\hline Female (n, \%) & $77(43.7)$ \\
\hline Birth weight $(g$, mean \pm S.D) & $2644.35 \pm 413.15$ \\
\hline Head circumference $(\mathrm{cm}$, mean \pm S.D) & $32.47 \pm 2.13$ \\
\hline Umbilical cord blood lead level $(\mu g / d L$, mean \pm S.D) & $5.15 \pm 12.65$ \\
\hline \multicolumn{2}{|l|}{ Fetal obstetrical problem (n, \%) } \\
\hline Yes & $6(3.4)$ \\
\hline No & $157(89.2)$ \\
\hline Unknown & $13(7.4)$ \\
\hline
\end{tabular}

Specific disorder in fetus/neonate $(n, \%)$

Yes

$17(9.6)$

No

$145(82.4)$

Unknown

$14(8.0)$

\begin{tabular}{lr} 
Maternal obstetrical problem $(\mathrm{n}, \%)$ & $44(25.0)$ \\
Yes & $119(67.6)$ \\
No & $13(7.6)$ \\
Unknown & $59(33.5)$ \\
\hline Problem noted during labor (n, \%) & $109(61.9)$ \\
Yes & $8(4.6)$ \\
No & 8 (4) \\
Unknown & 13
\end{tabular}

\begin{tabular}{lr}
\hline Use of oxytoxic agents during labor $(\mathrm{n}, \%)$ & $44(25.0)$ \\
Yes & $127(72.2)$ \\
No & $5(2.8)$ \\
Unknown & $135(76.7)$ \\
\hline Rupture of membranes before labor onset $(\mathrm{n}, \%)$ & $29(16.5)$ \\
No & 29.5
\end{tabular}


Table I: Characteristics of the neonatal study subjects $(n=176)$ (Continued)

\begin{tabular}{|c|c|}
\hline 24 to less than 72 hours & $5(2.8)$ \\
\hline 72 to less than 120 hours & $\mathrm{I}(0.6)$ \\
\hline More than 120 hours & $\mathrm{I}(0.6)$ \\
\hline Unknown & $5(2.8)$ \\
\hline \multicolumn{2}{|c|}{ Maternal medical problem during this pregnancy $(n, \%)$} \\
\hline Yes & $30(17.1)$ \\
\hline No & $137(77.8)$ \\
\hline Unknown & $9(5.1)$ \\
\hline \multicolumn{2}{|c|}{ Tobacco intake by mother $(\mathrm{n}, \%)$} \\
\hline No & $164(93.2)$ \\
\hline Yes & $8(4.6)$ \\
\hline Unknown & $4(2.2)$ \\
\hline \multicolumn{2}{|l|}{ Alcohol intake by mother (n, \%) } \\
\hline Yes & $3(1.8)$ \\
\hline No & $169(96.0)$ \\
\hline Unknown & $4(2.2)$ \\
\hline \multicolumn{2}{|l|}{ House painted $(n, \%)$} \\
\hline No or white wash & $98(55.7)$ \\
\hline Yes, some & $35(19.9)$ \\
\hline Yes, complete & $39(22.2)$ \\
\hline Unknown & $4(2.2)$ \\
\hline \multicolumn{2}{|l|}{ Age of house paint (n, \%) } \\
\hline$<5$ years & $62(83.8)$ \\
\hline $5-10$ years & $7(9.5)$ \\
\hline Unknown & $5(6.7)$ \\
\hline \multicolumn{2}{|c|}{ NBAS cluster scores (mean \pm S.D) } \\
\hline Habituation & $28.91 \pm 3.29$ \\
\hline Orientation & $43.06 \pm 8.19$ \\
\hline Motor & $26.60 \pm 3.69$ \\
\hline Range of state & $16.05 \pm 3.83$ \\
\hline Regulation of state & $18.69 \pm 5.38$ \\
\hline Autonomic stability & $14.12 \pm 3.29$ \\
\hline Abnormal reflexes & $2.37 \pm 1.98$ \\
\hline
\end{tabular}


score for each NBAS cluster as an outcome. For estimating the unadjusted influence, we used only CBL level as the predictor. Subsequently in a multiple linear regression model we estimated the adjusted influence of CBL for each NBAS cluster score by including the covariates mentioned above, the initial and predominant states of arousal (Table 2). It was essential to include both initial and predominant states in the multiple regression models because there two variables were not completely collinear with each other indicating that in a given infant often the initial state was not the same as the predominant state (Spearman's rho $=0.093, \mathrm{p}=0.1938$ ). Lastly, only for the "abnormal reflexes" cluster we used single and multiple Poisson regression analyses because the scores for this cluster actually represent the count of the number of abnormal reflexes.

Our next step of analysis was to assess the association of the CBL levels with the NBAS cluster scores in a multivariate context. For this purpose, we first conducted analysis of covariance (ANCOVA) using each NBAS cluster as the outcome and CBL as the predictor - first alone (unadjusted analysis) and then using initial and predominant states as covariates (adjusted analysis). Using the results from these analyses, we tested for the influence of blood lead on multiple outcomes using the Multiple Indicator Multiple Causes (MIMIC) model under the umbrella of Structural Equations Modeling (SEM). The details of the MIMIC model that we employed in our analyses are described below.

Additionally, we used Poisson regression to test the association between blood lead and the number of abnormal reflexes and multiple logistic regression analysis to test the association between various reflexes and dichotomized values of blood lead as described in the succeeding sections. We used Stata 8.0 (Stata Corp, College Station, TX) and Amos 5.0 (Amos Development Corp, Spring House, PA) for statistical analyses. Unless specified otherwise, an alpha error rate of 0.05 was used to test statistical significance.

\section{Results}

The characteristics of the study subjects are described in Table 1 and Supplementary Table 1 (see additional file 1, supplementary table 1$)$. Only two $(1.1 \%)$ neonates were premature ( $<32$ weeks), $10(11.3 \%)$ had head circumference less than $30 \mathrm{~cm}$, eight $(4.6 \%)$ were small (birth weight $<2 \mathrm{~kg}$ ), three $(1.7 \%)$ were very small (birth weight $<1.5 \mathrm{~kg})$ and $14(8.0 \%)$ had cord blood lead exceeding 10 $\mu \mathrm{g} / \mathrm{dL}$. In general, therefore our study sample mostly included healthy neonates. This was also reflected by the mean scores for each of the NBAS clusters as shown in Table 1. During the NBAS evaluation, the most common initial states were light sleep (65 neonates, 36.9\%), deep sleep (43 neonates, 24.4\%) and alertness (35 neonates, $19.9 \%$ ) while the most common predominant states were alertness (70 neonates, 39.7\%), open eyes (49 neonates, $27.8 \%$ ) and crying (31 neonates, $17.6 \%$ ).

\section{CBL and NBAS cluster scores}

The results shown in Table 2 indicated that when the analyses were conducted in all study subjects, the CBL levels significantly correlated with the autonomic stability and abnormal reflexes clusters even after adjustment for the aforementioned covariates. However, when the same analyses were performed in neonates with CBL levels $<10$ $\mu \mathrm{g} / \mathrm{dL}$, the unadjusted analyses identified the association of the CBL levels with the range of state and regulation of state clusters but the adjusted model identified the association with orientation and regulation of state clusters. We also considered whether the association of CBL with each NBAS cluster is specifically influenced by the potential effect of the initial and predominant states of the newborn on the NBAS cluster scores and found, using ANCOVA, that it was not (see additional file 1, supplementary table 2). This first pass analysis through the multiple regression models and ANCOVA thus indicated that i) The CBL lev-

Table 2: Results of regression analyses for prediction of NBAS cluster scores based on CBL and other covariatest in all neonates (left column) and neonates with CBL levels $<10 \mu \mathrm{g} / \mathrm{dL}$.

\begin{tabular}{lcccc}
\hline NBAS cluster & \multicolumn{2}{c}{ All Neonates } & Neonates with CBL $<10 \mu \mathbf{g} / \mathbf{d L}$ \\
\hline & Unadjusted (coefficient, $\mathrm{p}$ ) & Adjusted (coefficient, $\mathrm{p}$ ) & Unadjusted (coefficient, $\mathrm{p}$ ) & Adjusted (coefficient, $\mathrm{P}$ ) \\
\hline Habituation & $0.0145,0.468$ & $0.0292,0.213$ & $-0.0432,0.812$ & $-0.0057,0.988$ \\
Orientation & $0.0092,0.853$ & $0.0176,0.753$ & $0.2823,0.518$ & $1.5972,0.053$ \\
Motor & $0.0188,0.446$ & $0.0108,0.724$ & $-0.2733,0.136$ & $0.4154,0.282$ \\
Range of state & $-0.0304,0.196$ & $-0.0419,0.085$ & $-0.5135,0.008$ & $-0.1957,0.548$ \\
Regulation of state & $0.0030,0.930$ & $0.0458,0.336$ & $-0.7138,0.010$ & $-1.2912,0.036$ \\
Autonomic stability & $-0.0567,0.008$ & $-0.0506,0.077$ & $-0.1219,0.462$ & $-0.3156,0.507$ \\
Abnormal reflexes* & $0.0118,6.8 \times 10-5$ & $0.0073,0.084$ & $-0.0487,0.163$ & $-0.1049,0.168$
\end{tabular}

† List of the covariates is provided in the Methods section, Study Variables subsection

* Estimated using Poisson regression analysis 
els correlated with specific NBAS clusters; ii) The CBL levels were differentially associated with NBAS clusters in all subjects versus subjects with CBL levels below $10 \mu \mathrm{g} / \mathrm{dL}$ and iii) The association of CBL levels with NBAS clusters varied between the unadjusted and adjusted analyses in neonates with low-dose prenatal lead exposure.

\section{Correlation among NBAS cluster scores}

Even though the NBAS clusters are theoretically uncorrelated, we assessed if the correlations among these clusters were dataset-specific. To consider this possibility and the implications thereof, we first assessed the correlation structure of the seven NBAS clusters in all neonates as well as in neonates with CBL levels below $10 \mu \mathrm{g} / \mathrm{dL}$ (Figure 1 and additional file 1, supplementary table 3 ). Not surprisingly, we observed that there were a number of statistically significant correlations between pairs of NBAS clusters. Specifically, the habituation, orientation and motor clusters were strongly correlated with each other while the range of state and regulation of state clusters showed a trend towards a significant correlation with each other in all neonates as well as in neonates with CBL levels below $10 \mu \mathrm{g} / \mathrm{dL}$. Arguably, this correlation structure can alter the interpretations regarding the simultaneous influence of the predictors on the NBAS clusters. Therefore, we chose to conduct further analyses in which we modeled the influence of CBL levels and other covariates simultaneously on the NBAS clusters.

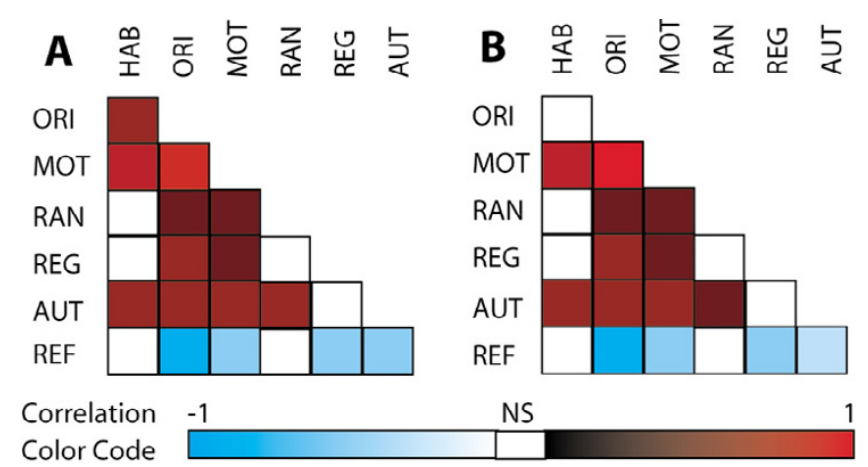

Figure I

Correlation structure of the NBAS cluster scores in all neonates $(A)$ and neonates with the CBL levels below $10 \mu \mathrm{g} / \mathbf{d L}$ (B). The color codes at the bottom provide a reference for the magnitude and significance of the Pearson correlation coefficients. Open boxes represent statistically non-significant correlation coefficient. The actual estimates of correlation coefficients and their significance values are shown in Supplementary Table 3 (see additional file I, supplementary table 3 ). The NBAS clusters shown here are: habituation (HAB), orientation (ORI), motor (MOT), range of state (RAN), regulation of state (REG) and autonomic stability (AUT) and abnormal reflexes (REF).

\section{Simultaneous effects of CBL on neonatal behavior: specification of the MIMIC model}

To be parsimonious, we wanted to select the most significant NBAS clusters that were least likely to be correlated with each other. For this purpose, using a reverse approach, we first used CBL levels as the outcome and the NBAS cluster scores as the predictors. We conducted stepwise linear regression with a strict retention probability criterion of 0.05 . The clusters that were retained in the final model (see additional file 1, supplementary table 4) were motor, autonomic stability and abnormal reflexes in all neonates and range of state in neonates with CBL levels below $10 \mu \mathrm{g} / \mathrm{dL}$. Therefore, we chose these four clusters as outcomes for modeling the simultaneous effects of CBL. This choice of the NBAS clusters was also consistent with the observed correlation structure since habituation and orientation were strongly correlated with the motor cluster while regulation of state was moderately correlated with the range of state.

We then chose four neonate-related predictors which we modeled as the covariates - CBL levels, head circumference, maturity and birth weight. There were three reasons for choosing this set of covariates. First, there exists literature support for a putative association of these covariates with NBAS cluster scores. Second, in a series of stepwise regression models in our dataset, these variables were consistently associated with one or more of the NBAS clusters (see additional file 1, supplementary table 5). Finally, as these variables can be considered to be of a continuous disposition, the correlation matrices to be used in structural equations modeling are more reliable and easier to construct and require no preprocessing of the data.

The path diagram of our model (Figure 2A) thus contained four predictors and four outcomes. In SEM, a model of this nature is referred to as the Multiple Indicator Multiple Causes (MIMIC) model [28]. In the proposed MIMIC model, none of the predictors directly influences any of the outcomes, that is, there exists no direct arrow in the path diagram (Figure 2A) from any predictor to any outcome - they all pass through a conceptual, latent and unmeasured variable. We argue that these four predictors influence a latent (unobserved) trait which we refer to as the "neonatal behavior". In our model, the NBAS clusters were thus considered as indicators of the neonatal behavior.

We modeled the influence of the predictors on neonatal behavior and on the four outcomes within the framework of structural equations modeling (SEM). The regression weights (parameters labeled as $r_{1}$ to $r_{7}$ in Figure 2A) thus measure the influence of the predictors on each outcome in a multivariate context. The random errors of measurement associated with all observed variables - four predic- 

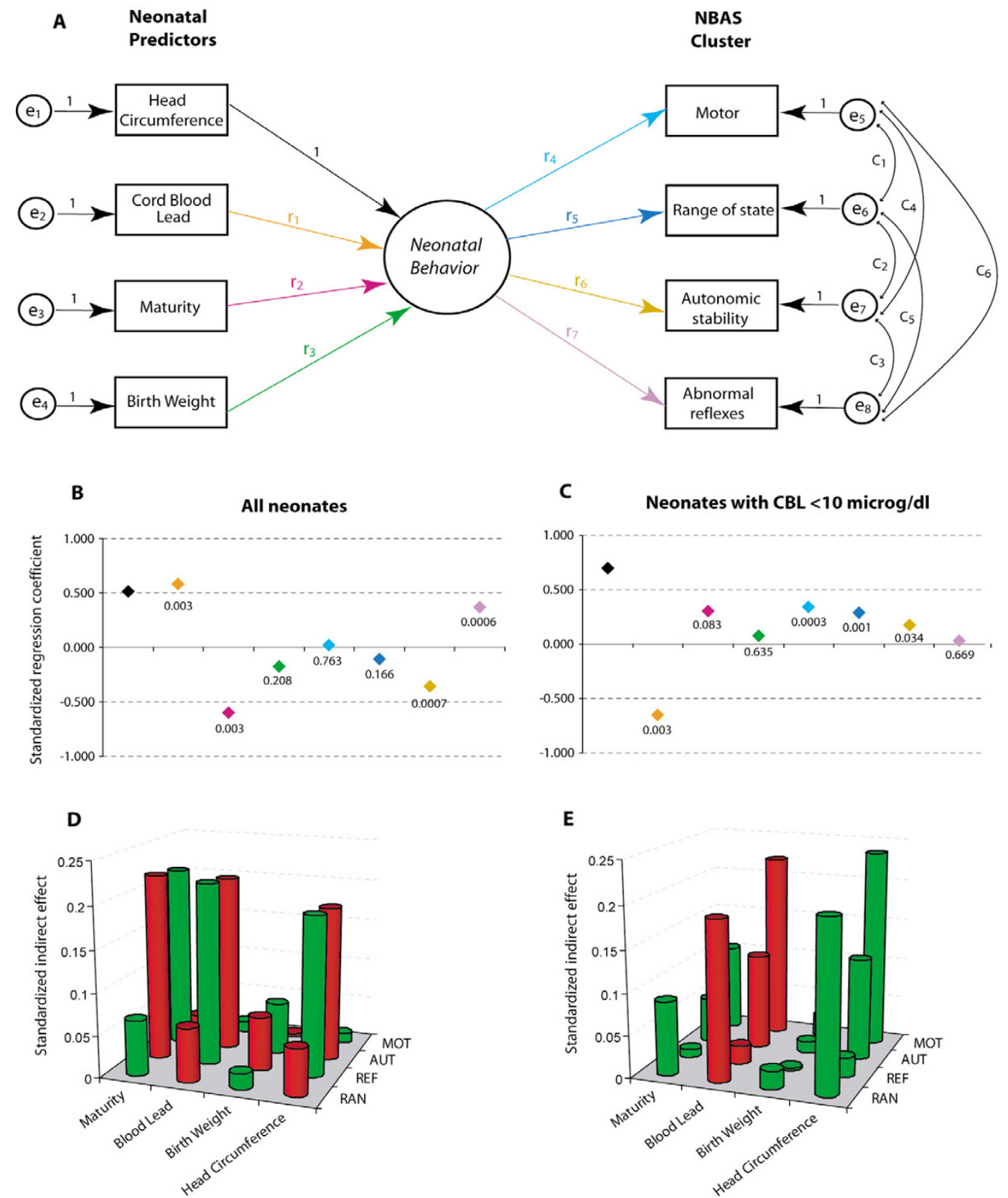

Figure 2

Structural equations modeling of the influence of neonatal predictors on the NBAS clusters. (A) The MIMIC model. The details of this model are given in text. Rectangles represent observed variables, circles represent latent variables, one-headed arrows represent influence and double-headed arrows represent covariance. The numbers or identifiers along the arrows are the model parameters. For ease of identification, the one-headed arrows of interest are color coded. Parameters $\mathrm{e}_{1}-\mathrm{e}_{8}$ represent the errors in measurement of observed variables. (B and C) Standardized regression coefficients for the color coded influences shown in panel A. Numbers indicate the statistical significance. The analysis was first conducted in all neonates (B) and then in neonates with CBL levels below $10 \mu \mathrm{g} / \mathrm{dL}(\mathrm{C})$. (D and E) Standardized indirect effects of the neonatal predictors (x-axis) on the NBAS cluster scores (y-axis). The z-axis represents the magnitude of the effect. Red cylinders indicate a negative effect while green cylinders indicate a positive effect. The analysis was conducted in all neonates (D) and then in neonates with CBL levels below $10 \mu \mathrm{g} / \mathrm{dL}$ (E). Complete results of SEM are shown in Supplementary Table 6 (see additional file I, supplementary table 6). Abbreviations for the NBAS clusters are: motor (MOT), range of state (RAN), autonomic stability (AUT) and abnormal reflexes (REF). 
Table 3: Association of NBAS items with risk of possessing high CBL levels: results from final models using stepwise multiple logistic regression analyses.

\begin{tabular}{|c|c|c|c|}
\hline \multirow[t]{2}{*}{ NBAS Item } & \multicolumn{3}{|c|}{$\begin{array}{c}\text { Risk of CBL levels }>\text { the shown cut-off } \\
\text { point }\end{array}$} \\
\hline & OR & $95 \% \mathrm{Cl}$ & $P$ \\
\hline \multicolumn{4}{|c|}{$5 \mu \mathrm{g} / \mathrm{dL}$} \\
\hline \multicolumn{4}{|l|}{ Range of State cluster } \\
\hline Peak of excitement & 0.60 & $0.37-0.98$ & 0.042 \\
\hline \multicolumn{4}{|l|}{$\begin{array}{l}\text { Autonomic stability } \\
\text { cluster }\end{array}$} \\
\hline Tremors & 0.77 & $0.63-0.94$ & 0.012 \\
\hline \multicolumn{4}{|l|}{ Abnormal reflexes } \\
\hline Moro's reflex & 3.37 & $1.13-10.04$ & 0.029 \\
\hline Walking reflex & 3.55 & $1.24-10.15$ & 0.018 \\
\hline \multicolumn{4}{|c|}{$10 \mu \mathrm{g} / \mathrm{dL}$} \\
\hline \multicolumn{4}{|l|}{$\begin{array}{l}\text { Autonomic stability } \\
\text { cluster }\end{array}$} \\
\hline Tremors & 0.75 & $0.58-0.96$ & 0.023 \\
\hline \multicolumn{4}{|l|}{ Abnormal reflexes } \\
\hline Babinski sign & 4.26 & $1.01-17.8$ & 0.047 \\
\hline Walking reflex & 5.99 & $1.44-24.9$ & 0.014 \\
\hline \multicolumn{4}{|c|}{$25 \mu \mathrm{g} / \mathrm{dL}$} \\
\hline \multicolumn{4}{|l|}{ Abnormal reflexes } \\
\hline Babinski sign & 11.3 & $1.89-68.1$ & 0.008 \\
\hline Walking reflex & 8.17 & $1.36-49.2$ & 0.022 \\
\hline
\end{tabular}

tors and four outcomes - were included as shown (parameters labeled as $e_{1}$ to $e_{8}$ in Figure 2A). Since the measurements of NBAS clusters are correlated, we assume that the measurement errors associated with these variables will also be correlated (shown by the curved arrows in the model and the parameters labeled as $c_{1}$ to $c_{6}$ ). Finally, to make the model identifiable, we constrained the head circumference $\rightarrow$ neonatal behavior regression weight to unity.

\section{Results from the MIMIC model}

Figure 2B-E and Supplementary Table 6 (see additional file 1, supplementary table 6) show the results of SEM analyses using the MIMIC model. As the predictor and outcome variables are measured on different metrics, we present the data in the form of standardized estimates of the regression coefficients (Figure $2 \mathrm{~B}$ and 2C). We observed that when the analysis was conducted in all neonates, CBL levels and maturity independently influenced neonatal behavior - more mature neonates had a better behavior score. Interestingly, this influence of CBL and maturity was detectable only with respect to autonomic stability and abnormal reflexes - the other two out- comes were not influenced. This analysis thus recaptured the observations from the previous analysis that even in a multivariate and multiple-outcome context the independent influence of CBL on autonomic stability and abnormal reflexes was discernible.

When the analysis was restricted to neonates with CBL levels below $10 \mu \mathrm{g} / \mathrm{dL}$, we observed a notable shift in the pattern of association. The CBL levels were now the only statistically significant predictor and the influence on the neonatal behavior was limited to the motor, range of state and autonomic stability clusters. Thus, concordant with the earlier results, our results of MIMIC modeling reaffirmed that the dominant effects of CBL were different in all neonates compared to neonates with low-dose exposure to lead.

Our results of the SEM modeling indicated that the model fit was not adequate either for all neonates or for neonates with $\mathrm{CBL}<10 \mu \mathrm{g} / \mathrm{dL}$. We further investigated the reason for this apparent lack of fit for which purpose we assessed the predictive performance of 10 other models nested within the model shown in Figure 2A. While constructing the nested models, we considered all combinations of the four predictors taken three at a time and then taken two at a time. These 10 models and their performance is shown (see additional file 1, supplementary table 7) in Supplementary Tables 7A (for all neonates) and 7B (for neonates with $\mathrm{CBL}<10 \mu \mathrm{g} / \mathrm{dL})$. A close look at the model fits for these nested models revealed the following: i) Removal of CBL as a predictor from the MIMIC model always worsened the model fit; ii) Inclusion of maturity and head circumference was most of the times associated with a poor fitting model; iii) The best model for all neonates was with two predictors: CBL and maturity; and iv) The best model for neonates with $\mathrm{CBL}<10 \mu \mathrm{g} / \mathrm{dL}$ contained CBL and head circumference. Thus, the full model with all four predictors was associated with a poor model fit but we have shown it here only because it permitted us to study the effects of CBL adjusted for other potential confounders.

\section{Association of increased CBL levels on items within the significantly associated NBAS clusters}

Given the significant multivariate effects of CBL levels on the four NBAS clusters included in the MIMIC model analyses in the previous step, we next considered whether there were any specific items within these clusters that were associated with the risk of increased CBL levels. For this purpose, we dichotomized the CBL levels into high and low using three different cut-off points: 5, 10 and 25 $\mu \mathrm{g} / \mathrm{dL}$. Using each of these binary outcomes we used backward stepwise unconditional multiple logistic regression analyses with a probability criterion of 0.05 to identify the NBAS items most significantly associated with the likeli- 
hood of possessing CBL levels exceeding these cut-offs. The results of these analyses are shown in Table 3.

We observed that not all items within each cluster were significantly associated with the risk of an increased CBL level. For example, if a high value ( $>25 \mu \mathrm{g} / \mathrm{dL}$ ) for the CBL cut-off was used then only two abnormal reflexes - Babinski's sign and walking reflex - were significantly associated. At the currently used cut-off of $>10 \mu \mathrm{g} / \mathrm{dL}$, tremors were additionally identified to be significantly associated, while at a lower cut-off of $>5 \mu \mathrm{g} / \mathrm{dL}$, the peak of excitement also was significantly associated. Moreover, Moro's reflex rather than Babinski's sign was the significant abnormal reflex.

\section{Discussion}

In the process of human brain development the perinatal period characterizes a critical interval during which there is highest rate of brain development, rampant genesis of new synapses, widespread neuronal proliferation, and maximum density of the N-methyl-D-aspartate (NMDA) receptors [31-37]. The last of these facts bears a special relevance to lead neurotoxicity since it has been argued that the $\mathrm{Ca}^{++}$permeable NMDA receptors also act as the neuronal gateway for $\mathrm{Pb}^{++}$[38]. Therefore the newborn brain is especially prone to the toxic effects of environmental neurotoxicants [26] and can be expected to be sensitive to even low doses of lead exposure. Based on this biological rationale, using the NBAS administered within three days of birth and employing multivariate statistical approaches for analysis, we observed that umbilical cord blood lead levels were significantly associated with different aspects of the neonatal behavior even at relatively low doses of exposure.

\section{Study findings}

We observed that the association of CBL levels with NBAS clusters was differential in two respects. First, not all NBAS clusters were equally associated with the CBL levels. Biologically, since the development of the newborn brain is neither simultaneous nor equivalent across all areas [26,39-41]; it can be expected that the influence of lead may not be alike on all areas of the developing brain. Indeed, several experimental studies have demonstrated that in the rat models of lead toxicity, the predominantly affected brain areas include the hippocampus $[42,43]$, the hypothalamus [44], the prefrontal cortex [45], the temporal cortex [46] and the cerebellum [47]. In humans, the posterior hippocampus has been shown to be associated with behavior [48], the prefrontal cortex is known to control cognitive functions like language, abstract reasoning, problem solving, social interactions, and planning $[49,50]$, the temporal lobe along with portions of hippocampus and prefrontal cortex has been implicated in object working memory [51] while cerebellum is the known seat of locomotion control. Our findings that the motor, range of state, autonomic instability and the abnormal reflexes NBAS clusters were specifically associated with the CBL: i) corroborate the conjecture that all domains of neonatal behavior will not be equally influenced by exposure to lead; and ii) are consistent with the known behaviorrelated functions of those areas in the human brain that have been shown in animal studies to be the primary targets for the effects of exposure to lead.

Second, and more interestingly, we found that the NBAS clusters associated with CBL levels in all neonates were not the same as the NBAS clusters identified by restricting the analyses to low levels of exposure. In neonates with $\mathrm{CBL}<10 \mu \mathrm{g} / \mathrm{dL}$, we did not observe an association of the varying CBL levels with the abnormal reflexes cluster but did uncover an association with the motor cluster. These data indicate that relatively higher values of CBL will be needed for lead to demonstrate its influence on the abnormal reflexes; however at a relatively milder dose it may continue to demonstrate an association with the motor, autonomic instability and range of state clusters. Evidence to support the deleterious effects of low-dose lead exposure on human neonatal behavior is continuously increasing $[24,25,52,53]$ however a novel finding of the present study is that the patterns of behavior are different in neonates with $\mathrm{CBL}<10 \mu \mathrm{g} / \mathrm{dL}$ as compared to those with a higher dose of exposure.

\section{Study limitations}

Our study suffers from three limitations. First, for the reasons explained earlier, the main focus of our study was the behavioral patterns in the newborn which we assessed using NBAS. However, this is a cross-sectional study design - a fact that does not permit inferences about the potential causal role of low-dose lead exposure $[25,54,55]$.

Second, a single measurement of umbilical cord blood lead is unlikely to faithfully capture the overall cumulative exposure to lead [25] thereby making our measurement of lead exposure questionable. We did not have data on serial measurements of the lead concentrations in mother's blood over the entire duration of pregnancy. Our rationale for using umbilical CBL was based on the following observations: i) As reported by previous studies, the correlation coefficient between maternal and umbilical cord blood lead levels ranges between 0.55 to 0.92 [56,57]; ii) All through gestation, lead is known to cross the placenta and is considered to be the most important source of umbilical cord blood lead [58]; and iii) independent of the maternal bone lead - an index of the cumulative lead exposure - umbilical cord blood lead has been shown to be a significant predictor of child development [25]. Considering these pieces of evidence from the 
literature and the absence of serial measurements of maternal blood lead in our study, we used umbilical cord blood lead as a surrogate for the cumulative lead exposure of the newborn.

Third, we did not have data on co-exposure of the newborn to other toxicants like cadmium and polychlorinated biphenyls which can also imitate some of the effects of lead $[54,59,60]$. In the absence of this data, our study will not be able to definitively point towards a causal role of lead, however the compatibility of our findings with the existing literature and the robust analytical methods used in this study urge the consideration of a plausible role of low-dose lead exposure in determining the patterns of neonatal behavior.

\section{Study implications}

With the caveats mentioned in the preceding section, we believe that our study has three important implications. First, it is not currently known whether the neonates who are affected by the low levels of lead exposure grow into children more likely to be affected with regards to their overall mental health. However, it has been observed that children exposed to low doses of lead show suboptimal cognitive functioning and reduced intelligent quotients [12-14]. Further, the following observations indirectly suggest a strong link between the events in early neonatal life and childhood development: gestational low-dose exposure to lead in rats can lead to a significant future risk of alterations in monoaminergic metabolism during adulthood [61]; neonatal infection can result in robust hippocampal-dependent memory impairment in adulthood [62]; neonatal prefrontal cortex lesions can manifest in adult animals as behavioral disturbances [63]; and early life does have an influence on the behavioral patterns in later life [64]. Considering all these observations together, it is conceivable that neonates demonstrating behavioral disturbances secondary to lead exposure may continue to manifest these disturbances in childhood.

We believe that, among others, a possible reason for the discordance in the results and interpretations of the effects of low-dose lead exposure on neonatal behavior can be attributed to a lack of a standardized analytical protocol. Theoretically, lead can have multiple and simultaneous effects and we suggest that future studies need to incorporate statistical techniques like SEM to handle the data more efficiently and accurately. The use of Generalized Estimating Equations (GEE) for regressing the predictors [65] on multiple outcomes is another attractive alternative. In either case, the emphasis needs to be laid on the measurement and identification of a concomitant influence of blood lead - alone or with other predictors - on multiple outcomes related to behavior.
Another area of interest in the field of lead poisoning relates to the policies and practice of screening. Sargent and others [66] argue that in order to reduce the false positive error rate, it may be unwarranted to screen for children with blood lead levels between 10 and $15 \mu \mathrm{g} / \mathrm{dL}$. As an alternative, Binns et al [67] suggested high-risk population screening. In situations where blood lead tests may not be easily or inexpensively available, it has also been thought to consider the use of blood lead questionnaires $[68,69]$. In that vein, we identified only a few NBAS items to be specifically correlated with the risk of possessing high CBL levels. Our findings imply that peak of excitement, tremors and abnormal Babinski's sign and walking reflexes may together serve as a potential initial screen to identify neonates possessing moderate to high CBL levels. While our study was not designed to address the issue of screening for lead toxicity, our results suggest that neonates with the aforementioned characteristics may need a further evaluation with a special emphasis on lead poisoning.

\section{Conclusion}

Needleman [4] believes that we are now into a "fifth cycle" of understanding the effects of this commonest environmental toxicant. Our findings concur with the observation that the effects of reduced levels of blood lead only indicate a possible avoidance of the physical presentation of lead poisoning; they may not however preclude the more subtle behavioral repercussions that can continue to have a high impact on the social realm of the disease. Therefore efforts to reduce exposure to this physiologically redundant but environmentally toxic metal need to continue.

\author{
Abbreviations \\ CBL Cord Blood Lead \\ NBAS Neonatal Behavioral Assessment Scale \\ SEM Structural Equations Modeling \\ MIMIC Multiple Indicators, Multiple Causes \\ ANCOVA Analysis of covariance \\ CDC Centers for Disease Control
}

IQ Intelligence quotient

\section{Competing interests}

The author(s) declare that they have no competing interests. 


\section{Authors' contributions}

ABP conceptualized the study, participated in data collection, data management and the review of the manuscript. MRM contributed to the statistical analyses, created the illustrations, and contributed to the manuscript writing and review. TPT contributed to the review of the manuscript. HRK conducted the statistical analyses and wrote the manuscript. All authors read and approved the final version of the manuscript.

\section{Additional material}

\section{Additional file 1 \\ This MS Word file contains the seven Supplementary Tables alluded to in this manuscript. Supplementary Table 1 describes some covariates listed in Table 1 of the main text in more details. Supplementary Table 2 shows the results of ANCOVA analyses. Supplementary Table 3 shows the correla- tion coefficients between pairs of NBAS clusters and their statistical sig- nificance. The analysis is first shown in all neonates and then in neonates with $C B L<10 \mathrm{mg} / d \mathrm{~L}$. Supplementary Table 4 shows the results of final models from stepwise multiple linear regression models predicting the CBL levels based on the NBAS cluster scores. Supplementary Table 5 shows the results of the final models from stepwise multiple linear regression analyses of the covariates on each of the four NBAS clusters chosen for SEM anal- ysis. Supplementary Table 6 shows the results of the full SEM model. Lastly, Supplementary Table 7 shows the model fit indices for a total of 11 nested models. In Supplementary Tables 3 and $5-7$, the analyses are first shown for all neonates and then for neonates with $C B L<10 \mu \mathrm{g} / \mathrm{dL}$. Click here for file \\ [http://www.biomedcentral.com/content/supplementary/1744- 9081-2-22-S1.doc]}

\section{Acknowledgements}

This study was supported by grant 1004-94-6305 from International Clinical Epidemiology Network (INCLEN), Philadelphia, USA. We thank the National Environmental Engineering Research Institute (NEERI) Nagpur, India, for their help in analyzing the blood samples. We also thank Dr. Nandini Gokulchandran, Dr. Leena Dhande, the Department of Pediatrics and the Department of Gynecology and Obstetrics at Government Medical College, Nagpur, India for their assistance. Lastly, the authors gratefully acknowledge the critical reviews by two reviewers that lead to a significant improvement in the manuscript.

\section{References}

I. Ernhart $C B$ : Lead levels and confounding variables. Am J Psychiatry 1982, I39:1524.

2. Ernhart CB: Inconsistencies in the lead-effects literature exist and cannot be explained by "effect modification". Neurotoxicol Teratol 1995, 17:227-33. discussion 249-25I.

3. Ernhart CB: Lead effects research. Am J Public Health 1998, 88: $1879-\mid 880$.

4. Needleman H: Lead poisoning. Annu Rev Med 2004, 55:209-222.

5. Needleman HL, Landrigan PJ: What level of lead in blood is toxic for a child? Am J Public Health 2004, 94:8-9.

6. Scarr S, Ernhart CB: Of whistleblowers, investigators, and judges. Ethics Behav 1993, 3:199-206.

7. Oberto A, Marks N, Evans HL, Guidotti A: Lead $(\mathbf{P b}+\mathbf{2})$ promotes apoptosis in newborn rat cerebellar neurons: pathological implications. J Pharmacol Exp Ther 1996, 279:435-442.
8. Shen X, Wu S, Yan C: Impacts of low-level lead exposure on development of children: recent studies in China. Clin Chim Acta 200I, 3 I 3:217-220.

9. Dietrich KN, Ris MD, Succop PA, Berger OG, Bornschein RL: Early exposure to lead and juvenile delinquency. Neurotoxicol Teratol 200I, 23:5II-5I8.

I0. Pabello NG, Bolivar V]: Young brains on lead: adult neurological consequences? Toxicol Sci 2005, 86:21 I-2I3.

II. Bellinger DC, Hu H, Kalaniti K, Thomas N, Rajan P, Sambandam S, Ramaswamy $\mathrm{P}$, Balakrishnan K: A pilot study of blood lead levels and neurobehavioral function in children living in Chennai, India. Int I Occup Environ Health 2005, I I: | 38- | 43.

12. Canfield RL, Gendle MH, Cory-Slechta DA: Impaired neuropsychological functioning in lead-exposed children. Dev Neuropsychol 2004, 26:5 I3-540.

13. Canfield RL, Kreher DA, Cornwell C, Henderson CR Jr: Low-level lead exposure, executive functioning, and learning in early childhood. Neuropsychol Dev Cogn C Child Neuropsychol 2003, 9:35-53.

14. Chen A, Dietrich KN, Ware JH, Radcliffe J, Rogan WJ: IQ and blood lead from 2 to 7 years of age: are the effects in older children the residual of high blood lead concentrations in 2-year-olds? Environ Health Perspect 2005, I | 3:597-601.

I5. Chiodo LM, Jacobson SW, Jacobson JL: Neurodevelopmental effects of postnatal lead exposure at very low levels. Neurotoxicol Teratol 2004, 26:359-37I.

16. Ozmert EN, Yurdakok K, Soysal S, Kulak-Kayikci ME, Belgin E, Ozmert E, Laleli Y, Saracbasi O: Relationship between physical, environmental and sociodemographic factors and school performance in primary schoolchildren. J Trop Pediatr 2005, 5 I:25-32.

17. Pocock SJ, Smith M, Baghurst P: Environmental lead and children's intelligence: a systematic review of the epidemiological evidence. BM] 1994, 309: I I89- I I97.

18. Schwartz J: Low-level lead exposure and children's IQ: a metaanalysis and search for a threshold. Environ Res 1994, 65:42-55.

19. Holmes SE, Slaughter JR, Kashani J: Risk factors in childhood that lead to the development of conduct disorder and antisocial personality disorder. Child Psychiatry Hum Dev 200I, 3 I : 183-I93.

20. Stretesky PB, Lynch MJ: The relationship between lead exposure and homicide. Arch Pediatr Adolesc Med 200I, I 55:579-582.

21. Ernhart CB, Wolf AW, Kennard MJ, Erhard P, Filipovich HF, Sokol RJ Intrauterine exposure to low levels of lead: the status of the neonate. Arch Environ Health 1986, 41:287-29I.

22. Rothenberg SJ, Schnaas L, Cansino-Ortiz S, Perroni-Hernandez E, de la Torre P, Neri-Mendez C, Ortega P, Hidalgo-Loperena H, Svendsgaard D: Neurobehavioral deficits after low level lead exposure in neonates: the Mexico City pilot study. Neurotoxicol Teratol 1989, I I:85-93.

23. Emory E, Pattilo R, Archibold E, Bayorh M, Sung F: Neurobehavioral effects of low-level lead exposure in human neonates. Am J Obstet Gynelcol 1999, I 8 I:S2-SI I.

24. Shen X-M, Yan C-H, Guo D, Wu S-M, Li R-Q, Huang $H$, Ao L-M, Zhou J-D, Hong Z-Y, Xu J-D, Jin X-M, T J-M: Low level prenatal lead exposure and neurobehavioral development of children in the first year of life: A prospective study in Shanghai. Environ Res 1998, 79: I-8

25. Gomaa A, Hu H, Bellinger D, Schwartz J, Tsaih SW, Gonzalez-Cossio T, Schnaas L, Peterson K, Aro A, Hernandez-Avila M: Maternal bone lead as an independent risk factor for fetal neurotoxicity: a prospective study. Pediatrics 2002, I I 0: I I0- I I8.

26. Tronick EZ: The neonatal behavioral assessment scale as a biomarker of the effects of environmental agents on the newborn. Environ Health Perspect 1987, 74: 185-189.

27. Brazelton TB, Nugent JK: Neonatal Behavioral Assessment Scale 3rd edition. London: Mac Keith Press; 1995.

28. Lester BM, Als H, Brazelton TB: Regional obstetric anesthesia and newborn behavior: a reanalysis toward synergistic effects. Child Dev 1982, 53:687-692.

29. Lagesson V, Andrasko L: Direct determination of lead and cadmium in blood and urine by flameless atomic absorption spectrophotometry. Clin Chem 1979, 25:1948-1953.

30. Bollen KA: The General Model. In Structural equations with latent variables John Wiley \& Sons: New York; 1989:3 19-448

31. Bhutta AT, Anand KJ: Vulnerability of the developing brain. Neuronal mechanisms. Clin Perinatol 2002, 29:357-372. 
32. Rice $D$, Barone $S J r$ : Critical periods of vulnerability for the developing nervous system: evidence from humans and animal models. Environ Health Perspect 2000, I 08:5 I I-533.

33. Rakic P: Images in neuroscience. Brain development, VI: radial migration and cortical evolution. Am J Psychiatry 1998, I55:I|50-II5I.

34. Rakic P, Bourgeois J-P, Eckenhoff MF, Zecevic N, Goldman-Rakic PS: Concurrent overproduction of synapses in diverse regions of the primate cerebral cortex. Science 1986, 232:232-235.

35. Gould E, Cameron HA: Early NMDA receptor blockade impairs defensive behavior and increases cell proliferation in the dentate gyrus of developing rats. Behav Neurosci 1997, I I I:49-56.

36. Rao H, Jean A, Kessler JP: Postnatal ontogeny of glutamate receptors in the rat nucleus tractus solitarii and ventrolateral medulla. J Auton Nerv Syst 1997, 65:25-32.

37. Chahal H, D'Souza SW, Barson AJ, Slater P: Modulation by magnesium of $\mathbf{N}$-methyl-Daspartate receptors in developing human brain. Arch Dis Child Fetal Neonatal Ed 1998, 78:FI I6-FI20.

38. Toscano CD, Guilarte TR: Lead neurotoxicity: from exposure to molecular effects. Brain Dev Brain Res Rev 2005, 49:529-554.

39. Uylings HB, Malofeeva LI, Bogolepova IN, Jacobsen AM, Amunts K, Zilles $\mathrm{K}$ : No postnatal doubling of number of neurons in human Broca's areas (Brodmann areas 44 and 45)? A stereological study. Neuroscience 2005, 136:7/5-728.

40. Travis K, Ford K, Jacobs B: Regional dendritic variation in neonatal human cortex: a quantitative Golgi study. Dev Neurosci 2005, 27:277-287.

4I. Guillery RW: Is postnatal neocortical maturation hierarchical? Trends Neurosci 2005, 28:5 I 2-5I7.

42. Yu K, Yu SS, Ruan DY: Opposite effects of lead exposure on taurine- and HFS-induced LTP in rat hippocampus. Brain Res Bull 2005, 64:525-531

43. Booze RM, Mactutus CF: Developmental exposure to organic lead causes permanent hippocampal damage in Fischer-344 rats. Experientia 1990, 46:292-297.

44. Virgolini MB, Chen K, Weston DD, Bauter MR, Cory-Slechta DA: Interactions of chronic lead exposure and intermittent stress: consequences for brain catecholamine systems and associated behaviors and HPA axis function. Toxicol Sci 2005, 87:469-482.

45. Schneider $M$, Koch $M$ : Behavioral and morphological alterations following neonatal excitotoxic lesions of the medial prefrontal cortex in rats. Exp Neurol 2005, 195:185-198.

46. Ma T, Chen $\mathrm{HH}$, Lim DK, Hume AS, Ho IK: Excitatory amino acids and lead-induced neurotoxicity. J Toxicol Sci 1998, 23:|8|-|83.

47. Zhu ZW, Yang RL, Dong GJ, Zhao ZY: Study on the neurotoxic effects of low-level lead exposure in rats. J Zhejiang Univ Sci B 2005, 6:686-692.

48. Strange BA, Fletcher PC, Henson RN, Friston KJ, Dolan RJ: Segregating the functions of human hippocampus. Proc Natl Acad SC USA 1999, 96:4034-4039.

49. Wood JN, Grafman J: Human Prefrontal Cortex: processing and representational perspectives. Nature Reviews Neuroscience 2003, 4: 139-147.

50. Strange BA, Henson RN, Friston KJ, Dolan RJ: Anterior prefrontal cortex mediates rule learning in humans. Cereb Cortex 200I, I I:1040-1046

5I. Kaldy Z, Sigala N: The neural mechanisms of object working memory: what is where in the infant brain? Neurosci Biobehav Rev 2004, 28: I13-121.

52. Factor-Litvak P, Wasserman G, Kline JK, Graziano J: The Yugoslavia Prospective Study of environmental lead exposure. Environ Health Perspect 1999, 107:9-15.

53. Schnaas L, Rothenberg SJ, Flores MF, Martinez S, Hernandez C, Osorio E, Velasco SR, Perroni E: Reduced intellectual development in children with prenatal lead exposure. Environ Health Perspect 2006, I | 4:79|-797.

54. Bellinger DC: Assessing environmental neurotoxicant exposures and child neurobehavior: confounded by confounding? Epidemiology 2004, I 5:383-384.

55. Bellinger DC: Lead. Pediatrics 2004, I | 3:1016-1022.

56. Ernhart CB: A critical review of low-level prenatal lead exposure in the human: I. Effects on the fetus and newborn. Reprod Toxicol 1992, 6:9-19.
57. Gardella C: Lead exposure in pregnancy: a review of the literature and argument for routine prenatal screening. Obstet Gynecol Surv 200I, 56:23 I-238.

58. Wong GP, Ng TL, Martin TR, Farquharson DF: Effects of low-level lead exposure in utero. Obstet Gynecol Surv 1992, 47:285-289.

59. Carrillo-Ponce Mde L, Martinez-Ordaz VA, Velasco-Rodriguez VM, Hernandez-Garcia A, Hernandez-Serrano MC, Sanmiguel F: Serum lead, cadmium, and zinc levels in newborns with neural tube defects from a polluted zone in Mexico. Reprod Toxicol 2004, 19:149-154.

60. Stewart P, Reihman J, Lonky E, Darvill T, Pagano J: Prenatal PCB exposure and neonatal behavioral assessment scale (NBAS) performance. Neurotoxicol Teratol 2000, 22:21-29.

61. Antonio MT, Corpas I, Leret ML: Neurochemical changes in newborn rat's brain after gestational cadmium and lead exposure. Toxicol Lett 1999, 104: I-9.

62. Bilbo SD, Rudy JW, Watkins LR, Maier SF: A behavioural characterization of neonatal infection-facilitated memory impairment in adult rats. Behav Brain Res 2006, 169:39-47.

63. Schneider $M$, Koch $M$ : Behavioral and morphological alterations following neonatal excitotoxic lesions of the medial prefrontal cortex in rats. Exp Neurol 2005, I95: I85-198.

64. McEwen BS: Early life influences on life-long patterns of behavior and health. Ment Retard Dev Disabil Res Rev 2003, 9: |49-I54.

65. Bull SB: Regression models for multiple outcomes in large epidemiologic studies. Stat Med 1998, I 7:2179-2197.

66. Sargent JD, Dalton M, Klein RZ: Diagnostic testing unwarranted for children with blood lead 10 to 14 microg/dL. Pediatrics |999, | 03:e5|.

67. Binns HJ, Kim D, Campbell C: Targeted screening for elevated blood lead levels: populations at high risk. Pediatrics 200I, I08: | 364-1366.

68. Binns HJ, LeBailly SA, Fingar AR, Saunders S: Evaluation of risk assessment questions used to target blood lead screening in Illinois. Pediatrics 1999, 103:100-106.

69. Litaker D, Kippes CM, Gallagher TE, O'Connor ME: Targeting lead screening: The Ohio Lead Risk Score. Pediatrics 2000, 106:E69.

Publish with Biomed Central and every scientist can read your work free of charge

"BioMed Central will be the most significant development for disseminating the results of biomedical research in our lifetime. "

Sir Paul Nurse, Cancer Research UK

Your research papers will be:

- available free of charge to the entire biomedical community

- peer reviewed and published immediately upon acceptance

- cited in PubMed and archived on PubMed Central

- yours - you keep the copyright

BiolMedcentral 